\title{
Synthesis and characterization of Architecturally Modified Mesoporous-microporous MFI (Mobil Five) Zeolite with enhanced catalytic activity
}

Dhanju Mani Pathak ( $\nabla$ dhanjumani@gmail.com )

ADP College https://orcid.org/0000-0003-3368-6814

Pankaj Kumar Ghosh

Kishor Kr Shah

Anup K Talukdar

\section{Research Article}

Keywords: Mobil Five, XRD, TGA, Esterification, Benzyl alcohol

Posted Date: March 18th, 2021

DOI: https://doi.org/10.21203/rs.3.rs-312699/v1

License: (c) (1) This work is licensed under a Creative Commons Attribution 4.0 International License. Read Full License 


\section{Abstract}

Four samples MFI zeolites were synthesized in presence of carbon black particles with silica-alumina molar ratio of 100 and different silica to carbon mass ratio under autogeneous pressure without adding any promoter or organic solvent. The synthesis temperature and duration of crystallization were $473 \mathrm{~K}$ and $16 \mathrm{~h}$ respectively. A sample of MFI was also synthesized without adding carbon black under similar condition. The synthesized samples were characterized by different techniques such as X-ray diffraction, FT-IR spectroscopy, Scanning electron microscopy, TGA and N2 adsorption desorption. The samples exhibit high crystallinity. The particle size ranged from 2.8 to $7.3 \mu \mathrm{m}$. Mesopore to micropore ratios was found to increase with increasing silicon to carbon mass ratio. These structurally modified meso-micro zeolite showed enhanced activity in the benzyl alcohol esterification reaction.

\section{Introduction}

Zeolites are crystalline microporous materials with pore size $0.3-1.5 \mathrm{~nm}$ and they are widely used as heterogeneous catalysts in industry particularly in petrochemistry and oil refining. The use of zeolites in organic transformation, organic synthesis and adsorption -- has been also due to the green nature of the catalyst besides their inherent properties like acidity and basicity, shape selectivity, adsorption, ion exchange etc.. However, pore diameter constraint has limited their uses to reactions involving only molecules compatible to their pore diameter. The approach for obtaining a crystalline, highly acidic material with an appreciable amount of mesoporosity has become the centre of zeolite research for last few years. Desilication and dealumination can create mesopore, but there is chance of structure damage treatments. The hydrothermal synthesis of zeolite is in the presence of a template with mesoscopic dimensions like carbon black, carbon rods, carbon spheres or carbon nanofibers [1-3] has been reported recently. Post synthesis combustion of the carbon template by calcination, resultant zeolite crystal consists of extra voids in mesoporous size range. Jacobsen et. al have reported that the MFI zeolite with carbon black particles was synthesized in $72 \mathrm{~h}$ autoclavation time within temperature $180^{\circ} \mathrm{C}$ under autogeneous pressure [4]. By the modification of synthesis method, Schmidt et. al have reported that the autoclaving time was reduced to $24 \mathrm{~h}$ at temperature $175^{\circ} \mathrm{C}$ [5].

In an attempt to reduce the synthesis time a two step method is used in the present study to prepare micropore with mesopores MFI zeolites by using carbon black particles under autogeneous pressure without adding any organic solvent, promoter or sulphuric acid. This procedure is successfully employed for the synthesis of MFI zeolite using carbon black particles with different silica to carbon ratio. Such type of synthesis introduces mesopores in MFI zeolite and decreases its the crystal size. The catalytic studies of the synthesized materials are carried out with the esterification reaction of benzyl alcohol by acetic acid. In organic synthesis esterification reaction is one of the fundamental reactions and has great use [6]. Most of the esterification reactions were carried out in presence of sulphuric acid, hydrochloric acid and toxic materials which are environmentally hazardous and unacceptable. Considering the impact of these chemicals on environment, zeolites are used as acid catalyst in organic transformation [7-10]. The use of zeolite has great advantage because it can be reused. Further, zeolite is thermally and 
hydrothermally stable and more efficient catalyst for esterification reaction [11-13]. Microwave induced esterification was also carried out using ion-exchange resin which was compared with that of sulphuric acid [14].

In industries different esterification of organic acid by different alcohol is used extensively for different purpose $[6,15,16]$. In the present study the reaction of benzyl alcohol and acetic acid for esterification using modified ZSM-5, MCM-48 and SBA-1 catalysts. Benzyl acetate is the product of the reaction of benzyl alcohol and acetic acid in presence of conc. sulphuric acid [17] and it is an important ester.

\section{Experimental}

\subsection{Synthesis of MFI zeolite with and without carbon black particles}

Four samples of MFI zeolites were synthesized with silica alumina different silica to carbon mass ratios by using carbon black particles (Merck). One sample of MFI zeolite without carbon black particles but with same silica to alumina ratio was also synthesized. In all these synthesis tetrapropylammoniumbromide (TPABr) (Lancaster), sodium hydroxide $(\mathrm{NaOH})$ (Merck), sodium aluminate (Kemphasol), colloidal silica (National Chemicals) and deionized water were used. A typical two step procedure for the synthesis of MFI zeolite is stated below:

\section{Step 1: Preparation of the seeding gel}

The required amount of $\mathrm{NaOH}$ was dissolved in $36 \mathrm{~mL}$ of distilled water. $3.771 \mathrm{~g}$ of TPABr was added to the $\mathrm{NaOH}$ solution with continuous stirring. The mixture was then stirred for another 30 minutes. $3.889 \mathrm{~g}$ of colloidal silica was added slowly to the mixture with continuous stirring. The mixture was stirred for another one hour to get a homogeneous gel.

\section{Step 2:Preparation of the second gel}

Required amount $\mathrm{NaOH}$ was dissolved in a solution of $26 \mathrm{~mL}$ of distilled water and $0.410 \mathrm{~g} \mathrm{NaAlO}_{2} .72$ $\mathrm{mL}$ distilled water were then added and the mixture was stirred for $30 \mathrm{~min} .11 .131 \mathrm{~g}$ of colloidal silica was added to the mixture with continuous stirring and then the mixture was stirred for an hour to get a homogeneous gel..

Finally the seeding gel prepared in the step 1 was added slowly and with continuous stirring to the second gel and the mixture was stirred for $1 \mathrm{~h}$ to get a homogeneous mixture. The $\mathrm{pH}$ of the final gel was found to be 11.3. The gel was transferred into an autoclave and heated at $200^{\circ} \mathrm{C}$ for $16 \mathrm{~h}$. The solid product obtained was filtered, washed with distilled water and dried at room temperature overnight and then at $110^{\circ} \mathrm{C}$ for $6 \mathrm{~h}$. The sample was calcined at $480^{\circ} \mathrm{C}$ in a muffle furnace for $6 \mathrm{~h}$. The synthesized product was in sodium form.

For the synthesis of ZSM - 5 with carbon black particles, the same procedure was followed as above, only difference in this case was the addition of carbon black with desired proportion in the second step. Four 
samples of MFI using different $\mathrm{SiO}_{2}$ to carbon ratios were synthesized. The designation and gel composition are shown in the table 1.

\subsection{Preparation of the catalyst (ion exchange method)}

\section{Preparation of $\mathrm{NH}_{4} \mathrm{MFI}$ and $\mathrm{H}-\mathrm{MFI}$ :}

A definite amount of sodium form of MFI and $120 \mathrm{~mL}$ of $15 \% \mathrm{NH}_{4} \mathrm{NO}_{3}$ solution were taken in a $250 \mathrm{~mL}$ round bottomed flask and refluxed in an oil bath with constant stirring with the help of a magnetic stirrer at $90^{\circ} \mathrm{C}$ for $6 \mathrm{~h}$. The solution was decanted and the residue was again treated with $15 \% \mathrm{NH}_{4} \mathrm{NO}_{3}$ solution and the above procedure was repeated for another time. The solution was filtered, washed with distilled water, dried at room temperature for overnight and then at $110^{\circ} \mathrm{C}$ for $6 \mathrm{~h}$. Thus obtained MFI was in $\mathrm{NH}_{4}$ form. The $\mathrm{NH}_{4}$ MFI was calcined at $480^{\circ} \mathrm{C}$ to get the H-MFI. Conversion of Na-MFI to H-MFI is shown in scheme 1 .

\subsection{Characterization of the synthesized materials}

For the identification of phase and to determine crystallinity, the synthesized samples were analysed by

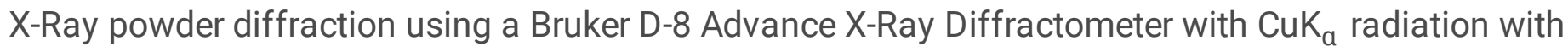
wavelength $1.5418 \AA$ operated at a voltage $40 \mathrm{kV}$ and current $40 \mathrm{~mA}$. The XRD patterns were taken in the $2 \theta=5-50{ }^{0}$ with step size $0.05^{\circ}$ and step time $0.5 \mathrm{~s}$. FTIR spectra were taken by using a Perkin Elmer RX 1 FT-IR Spectrophotometer by using KBr pallets in the mid IR region $4000-450 \mathrm{~cm}^{-1}$ (Resolution $8 \mathrm{~cm}^{-1}$ ). For the determination of particle morphology scanning electron micrograph of the synthesized MFI samples were taken by using LE01430VP; Carl Zeiss scanning electron microscope and Hitachi, S-3600 N scanning electron microscope. Thermo Gravimetric Analysis (TGA) analysis of all the synthesized samples were done by using Mettler Toledo TGA/DSC 1, STAR ${ }^{\text {e }}$ System analyzer in the temperature range 313-1173 $\mathrm{K}$ with heating rate of $10 \mathrm{~K} / \mathrm{min}$ in $\mathrm{N}_{2}$ gas atmosphere. The BET surface areas of the synthesized MFI samples and value of pore size were obtained from $\mathrm{N}_{2}$-absorption technique. Nitrogen adsorption/desorption measurement was carried out by using surface area and porosity analyzer instrument (Micromeritics; Tristar-3000). Prior to the experiments, all the samples were activated at $673 \mathrm{~K}$ for $2 \mathrm{~h}$ in high vacuum. After this treatment, liquid nitrogen was used to cool the samples to $74 \mathrm{~K}$. The samples were allowed to absorb nitrogen gas and complete isotherm was obtained. BET surface was calculated using t-plot method and pore size distribution (PSD) was calculated using Barrett-JoymerHalenda (BJH) formula.

\subsection{Esterification of benzyl alcohol by acetic acid over parent and modified MFI}

In the present study, the esterification reaction of benzyl alcohol by acetic acid using parent and modified $\mathrm{MFI}$ are carried out under different reaction time. The reactions were carried out in glass batch reactor under atmospheric pressure. The temperature of the reaction was controlled by a temperature controller and stirring was done by a magnetic stirrer. Before the use of catalysts in the reaction it was activated at 
$373 \mathrm{~K}$ temperature for $4 \mathrm{~h}$. The product and the unreacted reactants of the reaction were collected at different time intervals and analysed by Gas Chromatography (PEKIN ELMER, Clarus 500, Elite 501 column) to calculate the percentage of conversion under different reaction conditions.

\section{Results And Discussion}

The synthesized samples are identified from their XRD patterns. The XRD patterns of the zeolite samples MFI match with those of standard sample obtained from literature [18] and it is found that all the samples are highly crystalline. Figure 1 shows the XRD patterns of MFI samples synthesized without and with carbon black particles except ZC4 for which the same is shown in figure 2. From Fig 2 it is not clear whether MFI phase was really materialized or not, although IR spectra show the formation of required T-O bonds and basic units. The variation of full width at half maxima (FWHM) value with different $\mathrm{SiO}_{2}$ /carbon ratio is given in figure 3 .

For a particular crystallographic plane $(h k l)$, the crystallinity of MFI samples are calculated by using relation 1.

\section{See relation 1 and 2 in the supplementary files.}

Here $\beta$ is the full width at half maximum (FWHM); K is the shape factor (taken to be 0.9 ); $\theta_{\mathrm{hkl}}$ is the Bragg angle and $\lambda$ is the wavelength of CuKa1 (1.5418 $\AA$ ). The factor 5.73 is used to convert the value of $\beta$ from degree to radian order to obtain $D_{h k l}$ value in nanometer unit. The average crystallite size ranges from $28-58 \mathrm{~nm}$. The Crystallite size, percentage of Crystallinity $(\% \mathrm{C})_{h k l}$ of the synthesized samples is shown in table 2. From the table 2 , it is found that as the carbon content in the gel increases, the crystallite sizes of the MFI zeolites decreases. Crystal size of zeolite decreases with increase in mesoporosity. According to Thangaraj et.al [20], crystal size of zeolite decreases with increase in mesoporosity. In the present study mesoporosity of the synthesized samples increases as the carbon content increases (Table 2).

FT-IR spectra of parent (ZP) MFI and MFI samples synthesized in presence of C (ZC) is shown in figure 4. FT-IR results also confirm the formation of MFI zeolites in all cases showing absorption bands near 1080 (internal symmetric stretch), 790 (external symmetric stretch), 540 (double ring vibration) and $450 \mathrm{~cm}^{-1}$ (T-O bending.) [21]. The size and shape of the crystalline MFI zeolites were investigated by SEM analysis. The SEM micrographs of different samples such as parent, ZC1, ZC2 and ZC3 are shown in figures 5 (a), (b), (c) and (d) respectively. From the micrograph it is seen that the particles are cubic in shape and particle sizes ranges from 2.8 to $7.3 \mu \mathrm{m}$ and is given in table 3. Some cracks are shown in the particle as the carbon content increases. Moreover, it is found that the particle size increases with the increase in carbon content.

The TGA curves of ZC1, ZC2 and ZC3 are shown in figures 6(a), (b) and (c) respectively. The TGA curves show the initial mass loss up to $423 \mathrm{~K}$. This may be due to adsorbed water in the porous materials which 
means that the endothermic peak in the region $373-423 \mathrm{~K}$ can be assigned to the desorption of water in zeolite [22]. The second and third weight loss is due to the degradation of TPA ${ }^{+}$cations inside the zeolite structure [23]. The percentages of mass loss in the different regions of temperature are given in table 4.

Nitrogen adsorption-desorption isotherms of parent, ZC1, ZC2 and ZC3 samples are shown in figures $7(a), 7(b), 7(c)$, and $7(d)$. Significant changes in the $N_{2}$ adsorption-desorption isotherms are observed for ZC1, ZC2 and ZC3 samples. The adsorption-desorption isotherms of $\mathrm{N}_{2}$ of each sample show the typical type IV isotherm. At high pressure capillary condensation loops are observed for carbon containing samples ZC1, ZC2 and ZC3. Correspondingly bimodal pore systems are suggested for ZC1, $\mathrm{ZC2}$ and ZC3 as there are mesopores in these samples. The first capillary loops on the isotherms at $\mathrm{p} / \mathrm{p}_{\mathrm{o}}$ nearly in the ranges $0.20-0.5$ is characteristics of framework confined mesoporosity $[24,25]$. The second loops at $\mathrm{p} / \mathrm{p}_{\mathrm{o}}=0.6-1.0$ in the isotherm indicates the presence of secondary mesopores arising from intracrystalline voids in the packing of smaller crystals [26]. The carbon black particles produce mesoporosity in the MFI samples. The BET surface area and the average pore diameter of the synthesized MFI samples in different solvent are listed in table 5. As the carbon content increases in the gel, the micropore volume decreases from 0.15 to $0.05 \mathrm{~cm}^{3} \mathrm{~g}^{-1}$ [table 5] and total pore diameter increases from 20.64 to $27.51 \AA$. On the contrary mesopore volume is found to increase. This may be due to the conversion of some micropores into mesopores. The variation of BET surface area with the amount of $\mathrm{SiO}_{2}$ /carbon ratio is shown in figure 8 .

Esterification of benzyl alcohol by acetic acid was carried out over parent ZSM-5 and samples ZC1, ZC2 and ZC3 under $373 \mathrm{~K}$ temperature and up to duration of $10 \mathrm{~h}$. Benzyl alcohol reacts with acetic to produce benzyl acetate. The reaction is shown in scheme 2.The samples were collected at different time intervals such as $2 \mathrm{~h}, 4 \mathrm{~h}, 6 \mathrm{~h}, 8 \mathrm{~h}$ and $10 \mathrm{~h}$. The results for benzyl alcohol esterification on different catalysts under similar conditions at $373 \mathrm{~K}$ are summarized in table 6 and figure 9 . When the progress of the reaction was studied in different time intervals, it was observed that the conversion of the reaction increased in all cases with increase of reaction time. It has been observed that the conversion increases from 20.5 to $33.9 \%$, from 20.7 to $50.4 \%$, from 21.3 to $54.3 \%$, from 23.2 to $56.9 \%$ for the catalysts ZP, ZC1, ZC2 and ZC3 respectively. When time of reaction is increased from 2 to $4 \mathrm{~h}$, there is a difference of pattern in increase of conversion in case of catalyst ZP than other catalysts for increase of time of reaction from 4 to $6 \mathrm{~h}$ under similar conditions. It appears from the plot that the reaction tends to equilibrate after $8 \mathrm{~h}$ of reaction. Reaction conditions maintained in the reaction are temperature $=373 \mathrm{~K}$, catalyst amount $=0.2 \mathrm{~g}$, benzyl alcohol: acetic acid $=1: 2$ (molar ratio) and substrate volume $16 \mathrm{~mL}$. It is found that with the increase in carbon content, the \% conversion of the samples also increases, this may be due to increase in pore volume with the increase in carbon content.

\section{Conclusion}

MFI zeolites in presence of carbon black particles with different silica to carbon ratio and without carbon black particles were successfully synthesized in $16 \mathrm{~h}$ duration time without presence of promoter and 
organic solvent. XRD patterns of the synthesized samples confirm that the pure phases of MFI zeolite are formed and this is complemented by FT-IR data. The average crystallite sizes of the MFI zeolites are within the range $28-58 \mathrm{~nm}$ from XRD data. The crystal size of carbon containing MFI samples were decreased as the carbon contents in the gel increase indicating formation of mesopores in the zeolite crystals. The particle sizes ranges from 2.8 to $7.3 \mu \mathrm{m}$. The mesopore volume and pore diameter of the synthesized MFI zeolites are increases as the carbon content increases in the synthesized gel whereas micropore volume decreases as the carbon content increases in the synthesized gel. From the above result and discussion it may be concluded that some mesopores are introduced in the MFI zeolite materials. By analyzing the data of the esterification reaction, it is seen that the conversion of benzyl alcohol remains almost same in lower time for blank and catalyzed reactions. The selectivity towards benzyl acetate in all the cases is $100 \%$.

\section{Declarations}

\section{Acknowledgement}

The Authors acknowledge the centre for nanotechnology and CIF of IIT, Guwahati and Department of Instrumentation and USIC, Gauhati University for characterization of the samples.

\section{References}

1. H. Christensen, K. Johannsen, I. Schmidt, C. H. Christensen, Catalytic benzene alkylation over mesoporous zeolite single crystals: improving activity and selectivity with a new family of porous materials, J. Am. Chem. Soc. 125 (2003) 13370-13371.

2. Tao, K. Kanoh, K. Kaneko, ZSM-5 Monolith of Uniform Mesoporous Channels J. Am. Chem. Soc. 125 (2003) 6044-6045.

3. H. Janssen, I. Schmidt, C. J. H. Jacobsen, A. J. Koster, K. P. de Jong, Exploratory study of mesopore templating with carbon during zeolite synthesis, Micropor Mesopor. Mater. 65 (2003) 59-75.

4. C. J. H. Jacobsen, C. Madsen, J. Houzvicka, I. Schmidt, and A. Carlsson, Mesoporous zeolite single crystals, J. Am. Chem. Soc.122 (2000) 7116-7117.

5. I. Schmidt, A. Boisen, E. Gustavsson, K. Ståhl, S. Pehrson, S. Dahl, A. Carlsson, and C. J. H. Jacobsen, Carbon nanotube templated growth of mesoporous zeolite single crystals, Chem. Mater. 13(2001) 4416-4418.

6. R. C. Larock, Comprehensive Organic Transformations, VCH Publishers, New York, 1989 (Chapter 9).

7. R. A. Sheldon, R. S. Downing, Heterogeneous catalytic transformations for environmentally friendly production, Appl. Catal. A: Gen. 189 (1999) 163-183.

8. S. E. Sen, S. M. Smith, K. A. Sulivan, Organic transformations using zeolites and zeotype materials, Tetrahedron, 55 (1998) 12657-12689. 
9. A. Pandey, A. P. Singh, A novel catalytic method for the acylation of aromatics to the corresponding ketones over zeolite catalysts, Catal. Lett. 44 (1997) 129-133.

10. U. Freese, F. Heinrich, F. Roessner, Acylation of aromatic compounds on H-Beta zeolites, Catal. Today 49 (1999) 237-244.

11. Y. Ma, Q. L. Wang, H. Yan, X. Ji, Q. Qiu, Zeolite-catalyzed esterification I. Synthesis of acetates, benzoates and phthalates, Appl. Catal. A: Gen., 139 (1996) 51-57.

12. A. Corma, H. Garcia, S. Iborra, J. Primo, Modified faujasite zeolites as catalysts in organic reactions: Esterification of carboxylic acids in the presence of HY zeolites, J. Catal. 120 (1989) 78-88.

13. M. Lasperas, P. Graffin, P. Geneste, One-Pot Selective Synthesis of Ethyl Esters from Aromatic Nitriles Using Acid Faujasites as CatalystsJ. Catal. 139 (1993) 362-370.

14. K. G. Kabza, B. R. Chapados, J. E. Gestwicki, J. L. McGrath, J. Chem, 31(A) (1992) 803.

15. G. Sartori, R. Maggi, Use of Solid Catalysts in Friedel- Crafts Acylation Reactions, Chem Rev, 106 (2006) 1077-1104.

16. A. Zaidi, J. L. Gainer, G. Carta, Fatty acid esterification using nylon-immobilized lipase, Biotechnol. Bioeng., 48 (1995) 601-605.

17. A.I. Vogel, Text book of Practical Organic Chemistry, $3^{\text {rd }}$ edn (Longmans) , 1956, 783.

18. H. Robson, Verified synthesis of zeolitic materials, (Ed. K. P. Lillerud), Elsevier, Amsterdam, $2^{\text {nd }}$ edn, (2001).

19. B. D. Cullity, Elements of X-Ray diffraction, Addison Wesley Publishing Company Inc, London (1978) 286.

20. A.Thangaraj R.Kumar S.P.Mirajkar P.Ratnasamy, Catalytic properties of crystalline titanium silicalites I. Synthesis and characterization of titanium-rich zeolites with MFI structure, J. of Catal., 130 (1991) 1-8.

21. E. M. Flanigen, H. Khatani, H. A. Szymanski "Molecular Sieve Zeolites", Advan. Chem. Ser. 101, American Chemical Society, Washington, DC, (1971) 201.

22. M. A. Camblor, A. Corma, S. Valencia, Characterization of nanocrystalline zeolite Beta, Micropor Mesopor Mater, 25 (1998) 59-74.

23. J.E. H. A. Asswad, N. Dewaele, J. B. Nagy , R. A. Hubery, Z. Gabelica, E. G. Derouani, F. Crea, R. Aiello, A. Nastro, Identification of different tetrapropylammonium cations occluded in ZSM-5 zeolite by combined thermal analysis (t.g.-d.t.a.) and 13C-n.m.r. spectroscopy, Zeolites 8 (1988) 221-222.

24. X. Chen, L. Huang, G. Ding, Q. Li, Characterization and catalytic performance of mesoporous molecular sieves Al-MCM-41 materials, Catal. Lett. 44 (1997) 123-128.

25. B. X. Chen, L. Huang, Q. Li, Hydrothermal Transformation and Characterization of Porous Silica Templated by Surfactants, J. Phys. Chem. B, 101 (1997) 8460-8467.

26. Y. H. Chou, C.S. Cundy, A. A. Garforth, V. L. Zholobenko, Mesoporous ZSM-5 catalysts: Preparation, characterization and catalytic properties. Part I: Comparison of different synthesis routes, Micropor Mesopor Mater, 89 (2006) 78-87. 


\section{Tables}

Table 1 Designation and gel composition of different synthesized MFI samples

\begin{tabular}{|c|c|c|c|c|c|}
\hline Sample designation & $\mathrm{SiO}_{2} / \mathrm{Al}_{2} \mathrm{O}_{3}$ & $\mathrm{OH}^{-} / \mathrm{SiO}_{2}$ & $\mathrm{H}_{2} \mathrm{O} / \mathrm{SiO}_{2}$ & $\mathrm{TPA} / \mathrm{SiO}_{2}$ & $\mathrm{SiO}_{2} / \mathrm{C}$ \\
\hline $\mathrm{ZP}$ & 100 & 0.15 & 30 & 0.05 & - \\
\hline $\mathrm{ZC} 1$ & 100 & 0.15 & 30 & 0.05 & $1: 1$ \\
\hline $\mathrm{ZC} 2$ & 100 & 0.15 & 30 & 0.05 & $1: 4$ \\
\hline$Z C 3$ & 100 & 0.15 & 30 & 0.05 & $1: 8$ \\
\hline$Z C 4$ & 100 & 0.15 & 30 & 0.05 & $1: 12$ \\
\hline
\end{tabular}

Table 2 Crystallite size, percentage of Crystallinity (\%C) ${ }_{h k l}$

\begin{tabular}{|c|c|c|c|c|c|c|}
\hline \multirow{3}{*}{$\begin{array}{l}\text { For a particular } \\
\text { crystallographic plane }(h k l) \\
\text { where } \mathrm{I}_{h k l} \text { is the corrected } \\
\text { integral XRD peak } \\
\text { Sample }\end{array}$} & \multicolumn{3}{|c|}{ Crystallite size (nm) } & \multirow{3}{*}{$\begin{array}{c}(\% \mathrm{C})_{501} \\
\text { from } \\
\mathrm{XRD}\end{array}$} & \multirow{3}{*}{$\begin{array}{c}\text { Average } \\
\text { (\%C) } \\
\text { from } \\
\text { XRD }\end{array}$} & \multirow{3}{*}{$\begin{array}{l}\text { Average } \\
\text { crystallite } \\
\text { size (nm) }\end{array}$} \\
\hline & $(101)$ & (501) & (303) & & & \\
\hline & & & & & & \\
\hline Parent & 40.49 & 55.27 & 80.80 & 92.52 & 85.13 & 58.85 \\
\hline $\mathrm{ZC1}$ & 40.52 & 54.97 & 41.29 & 94.28 & 91.83 & 45.59 \\
\hline $\mathrm{ZC} 2$ & 40.53 & 41.25 & 50.09 & 95.84 & 89.26 & 43.96 \\
\hline ZC3 & 33.76 & 29.44 & 22.93 & 84.75 & 84.75 & 28.71 \\
\hline $\mathrm{ZC} 4$ & - & - & - & - & - & - \\
\hline
\end{tabular}

Table 3: Particle size of parent, ZC1, ZC2 and ZC3 


\begin{tabular}{|c|c|}
\hline Sample & Particle size $(\mu \mathrm{m})$ \\
\hline Parent & 2.8 \\
\hline ZC1 & 3.4 \\
\hline ZC2 & 4.4 \\
\hline ZC3 & 7.3 \\
\hline
\end{tabular}

Table 4 Mass \% loss of synthesized MFI samples at different temperature range.

\begin{tabular}{|c|c|c|c|}
\hline \multirow{2}{*}{ Samples } & \multicolumn{3}{|c|}{ Mass\% loss } \\
\cline { 2 - 4 } & 323K-573K & $573 \mathrm{~K}-773 \mathrm{~K}$ & 773K- 1073K \\
\hline ZC1 & 1.53 & 0.23 & 0.21 \\
\hline ZC2 & 1.96 & 0.71 & 0.08 \\
\hline ZC3 & 1.99 & 0.25 & 0.67 \\
\hline
\end{tabular}

Table 5 Summery of BET surface area and pore volume of Parent, ZC1, ZC2 and ZC3

\begin{tabular}{|c|c|c|c|c|}
\hline Sample & $\begin{array}{c}\text { BET surface area } \\
\left(\mathrm{m}^{2} \mathrm{~g}^{-1}\right)\end{array}$ & $\begin{array}{c}\text { Micropore volume } \\
\left(\mathrm{cm}^{3} \mathrm{~g}^{-1}\right)\end{array}$ & $\begin{array}{c}\text { Mesopore volume } \\
\left(\mathrm{cm}^{3} \mathrm{~g}^{-1}\right)\end{array}$ & $\begin{array}{c}\text { Pore } \\
\text { diameter }(\AA)\end{array}$ \\
\hline Parent & 341.39 & 0.1509 & 0.0720 & 20.64 \\
\hline ZC1 & 232.066 & 0.0985 & 0.1191 & 20.53 \\
\hline ZC2 & 233.54 & 0.0956 & 0.1249 & 21.39 \\
\hline ZC3 & 123.25 & 0.0544 & 0.1848 & 27.51 \\
\hline
\end{tabular}


Table 6 Comparison of (\%) conversions of esterification of benzyl alcohol with acetic acid over different catalysts at different time intervals.

\begin{tabular}{|c|c|c|c|c|}
\hline \multirow{2}{*}{ Time (h) } & \multicolumn{4}{|c|}{ Conversion (\%) } \\
\cline { 2 - 5 } & ZP & ZC1 & ZC2 & ZC3 \\
\hline 2 & 20.5 & 20.7 & 21.3 & 23.2 \\
\hline 4 & 28.4 & 28.9 & 28.9 & 30.5 \\
\hline 6 & 31.2 & 45.2 & 47.1 & 50.7 \\
\hline 8 & 33.7 & 50.1 & 54.1 & 56.5 \\
\hline 10 & 33.9 & 50.4 & 54.3 & 56.9 \\
\hline
\end{tabular}

\section{Figures}



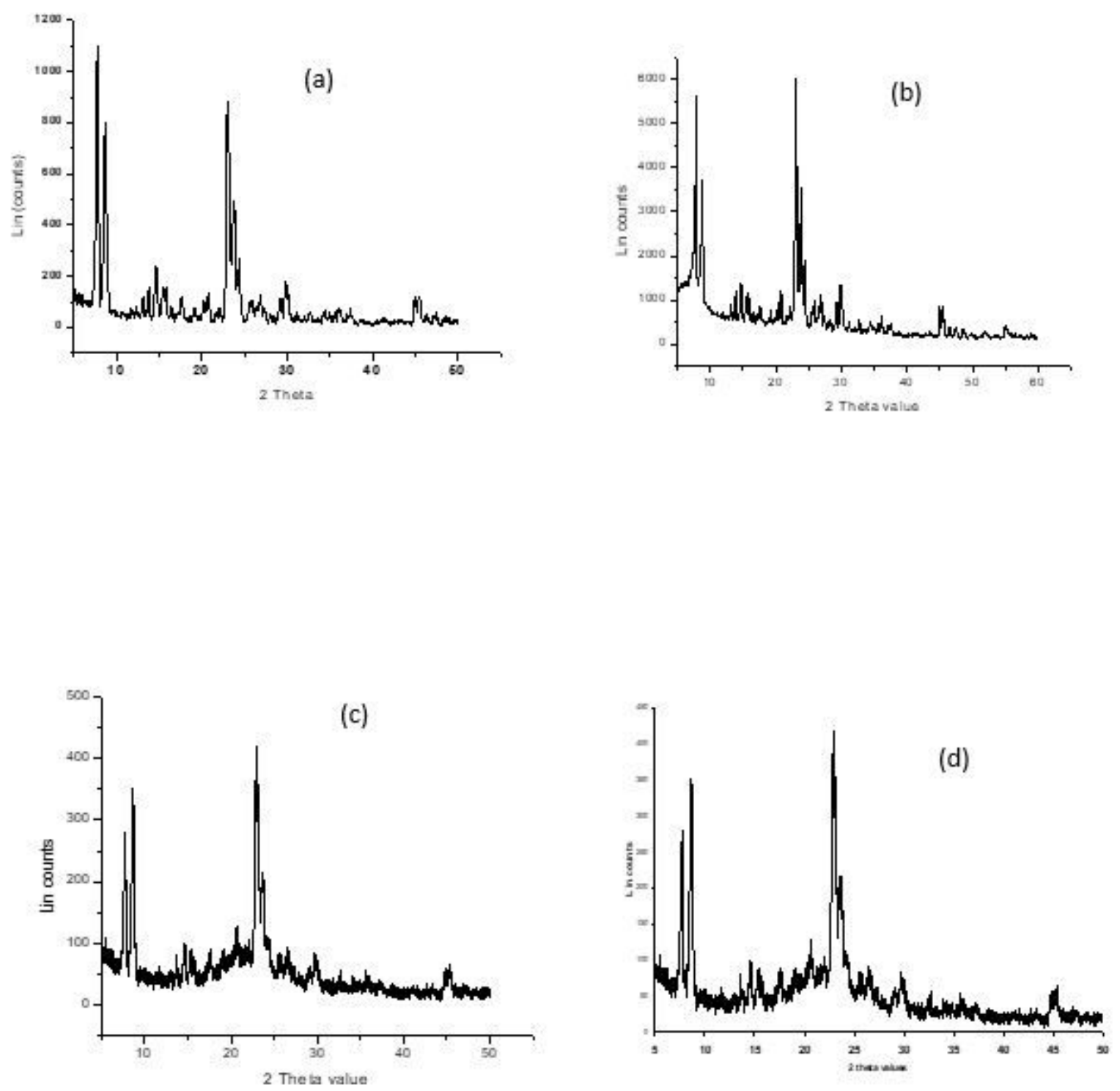

Figure 1

XRD pattern of (a )MFI (ZP) samples without carbon black particles with SAR 100 (b) ZC1, (c) ZC2 and (d) ZC3 


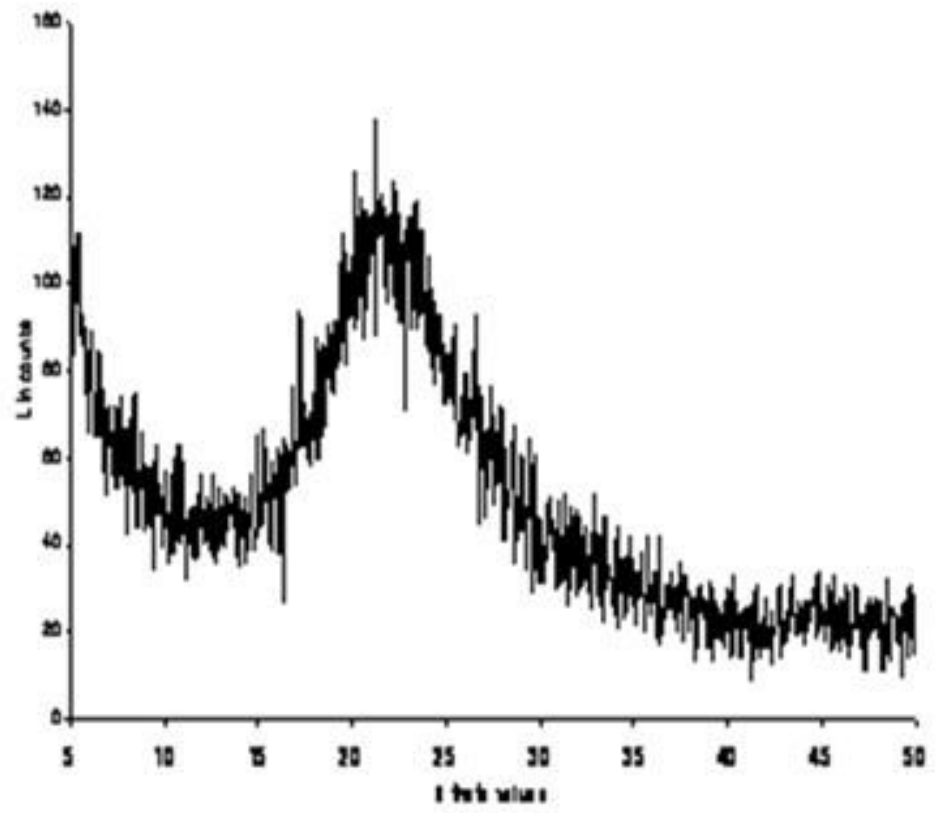

Figure 2

XRD of MFI (ZC4) in 1:12 SiO2/carbon ratio

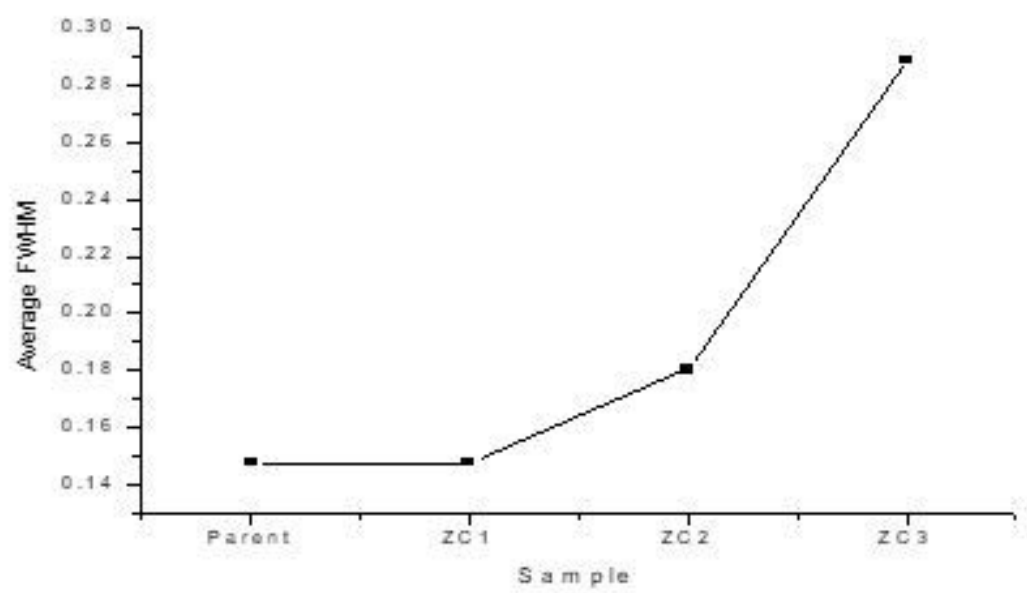

Figure 3

Variation of FWHM value for different $\mathrm{SiO} / \mathrm{C}$ 

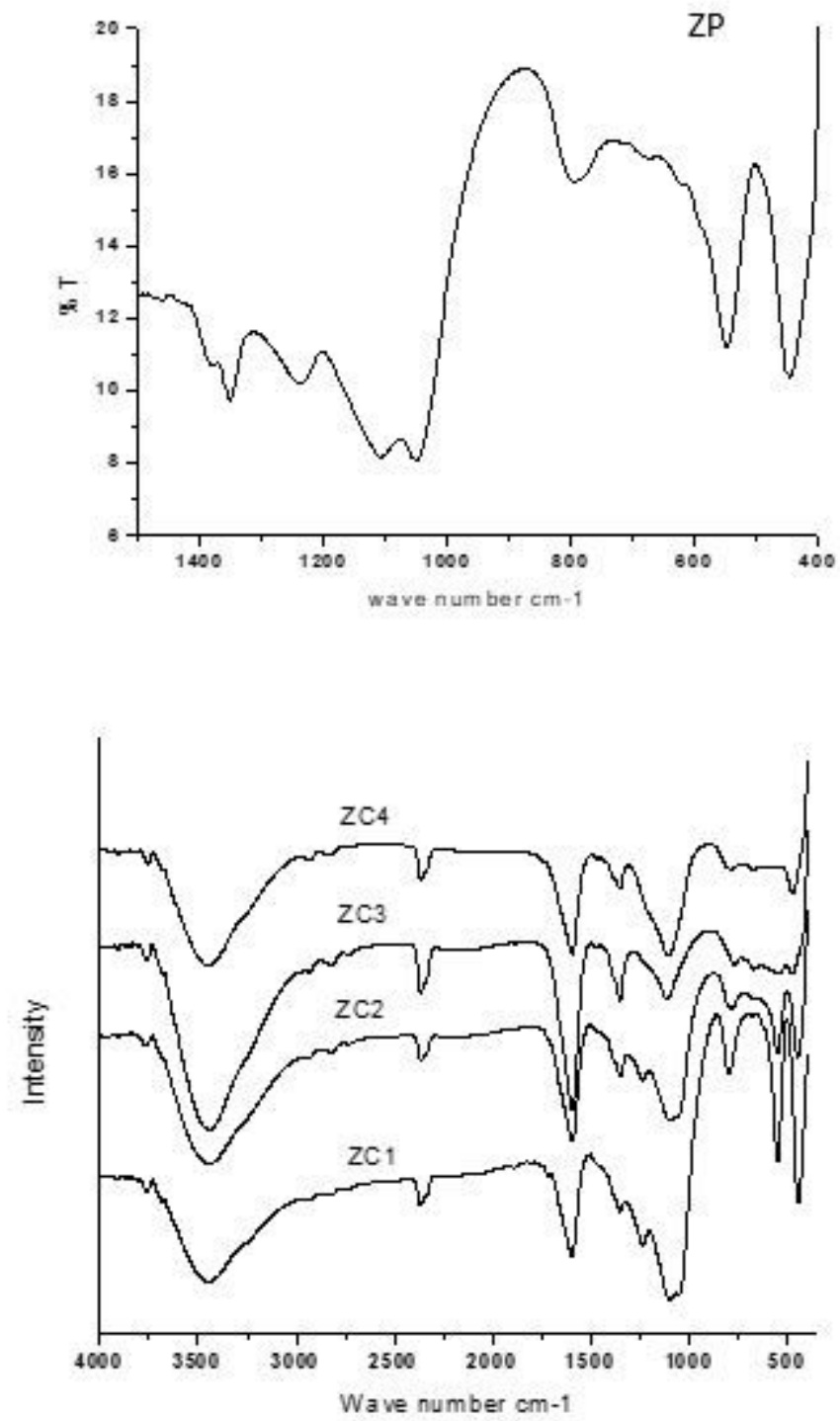

Figure 4

FT-IR spectra of parent (ZP) and modified (ZC) MFI samples 


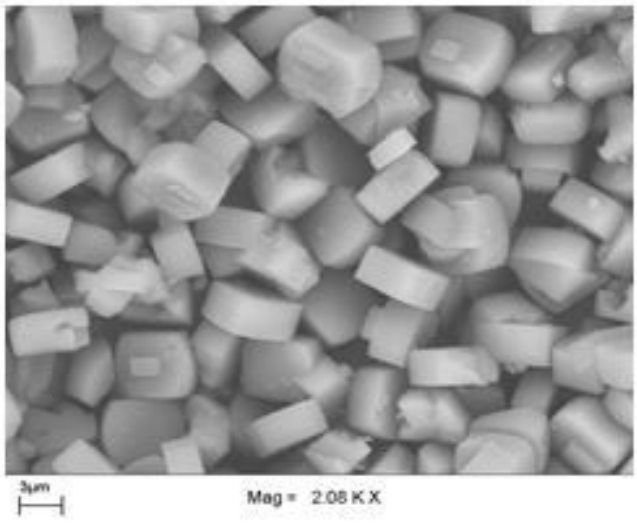

Fig 5(a) SEM image of MFI (parent)

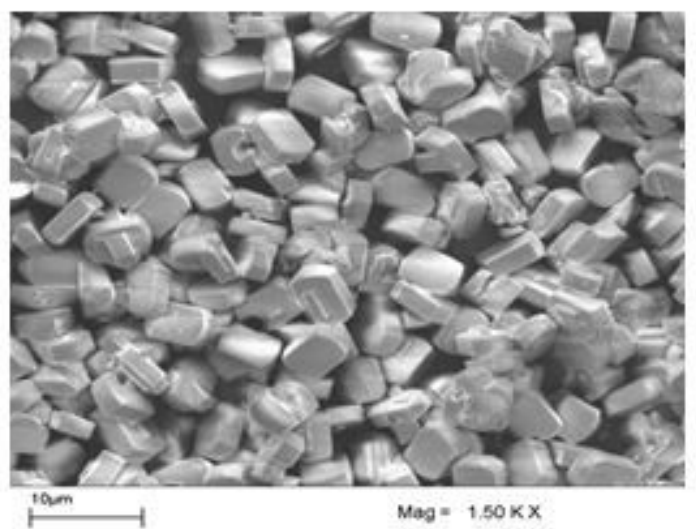

Fig 5(c) SEM image of MFI (ZC2) with $\mathrm{SiO}_{2} /$ carbon $=1: 4$

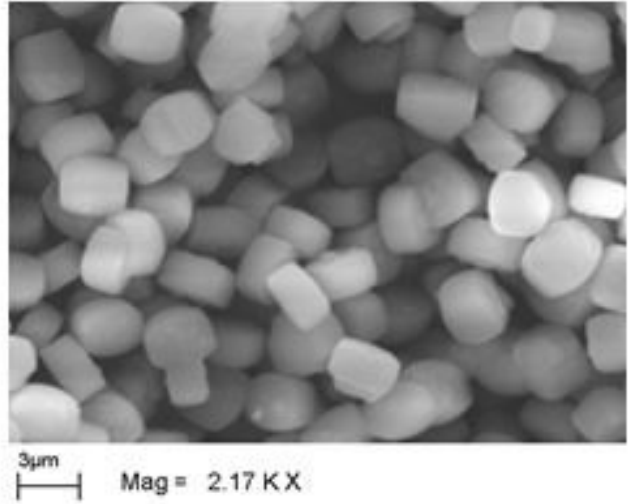

Fig 5(b) SEM image of MFI (ZC1) with $\mathrm{SiO}_{2} /$ carbon $=1: 1$

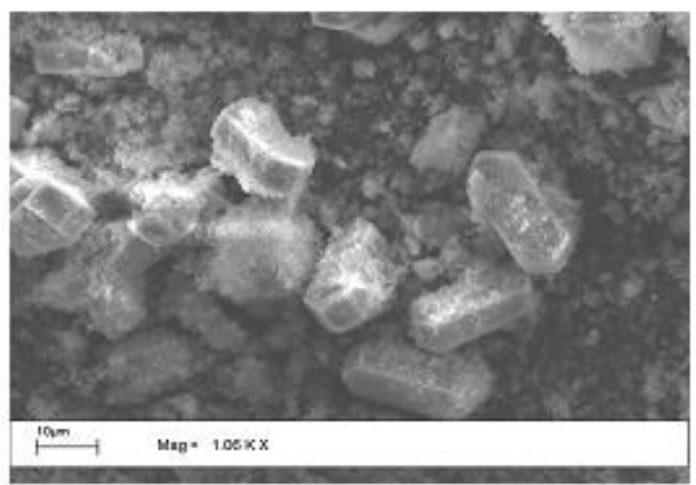

Fig 5(d) SEM image of MFI (ZC3) with $\mathrm{SiO}_{2} /$ carbon $=1: 8$

\section{Figure 5}

Fig 5(a) SEM image of MFI (parent) Fig 5(b) SEM image of MFI (ZC1) with SiO2/carbon = 1:1 Fig 5(c) SEM image of MFI (ZC2) with Fig 5(d) SEM image of MFI (ZC3) with SiO2/carbon = 1:4 SiO2/carbon $=1$ : 8
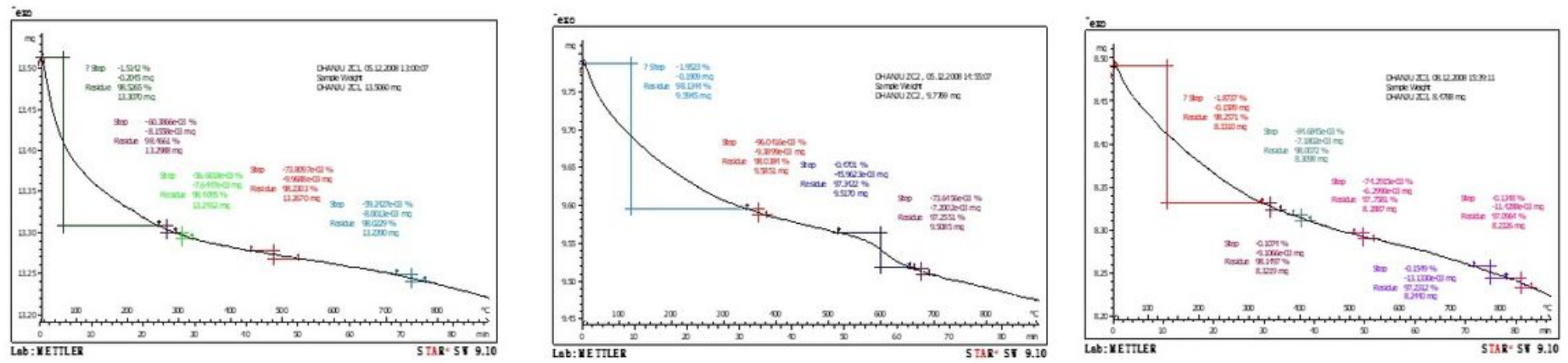

\section{Figure 6}


Fig. 6(a) TGA of sample ZC1. Fig. 6(b) TGA of sample ZC2. Fig. 6(c) TGA of sample ZC3
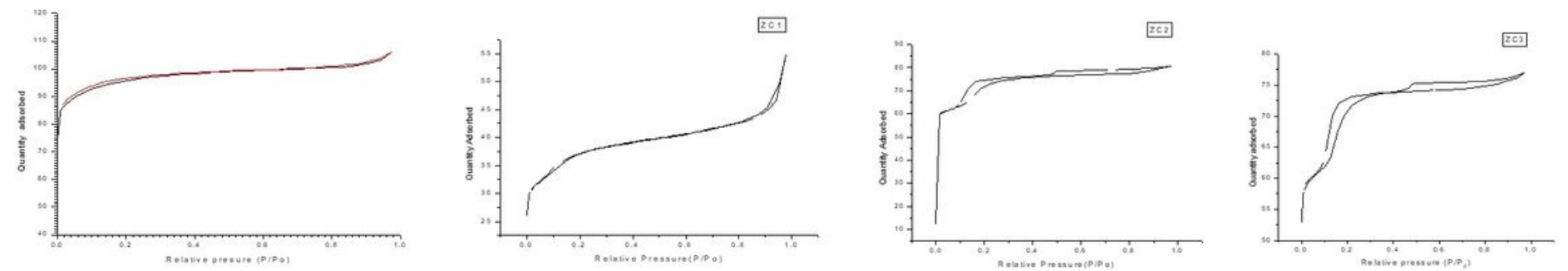

\section{Figure 7}

Fig 7(a) N2 Adsorption-desorption Isotherm of Parent MFI sample. Fig 7(b) N2 Adsorption-desorption Isotherm of ZC1. Fig 7(c) N2 Adsorption-desorption Isotherm of ZC2. Fig 7(d) N2 Adsorption-desorption Isotherm of ZC3

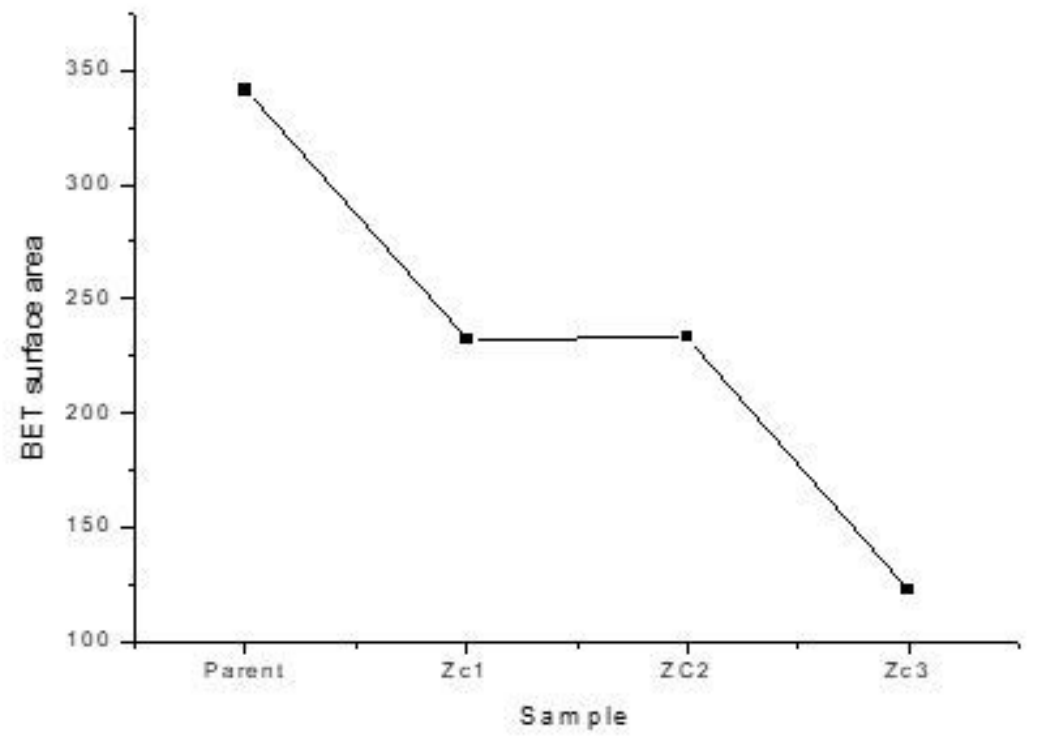

Figure 8

Variation of BET surface area with carbon content 


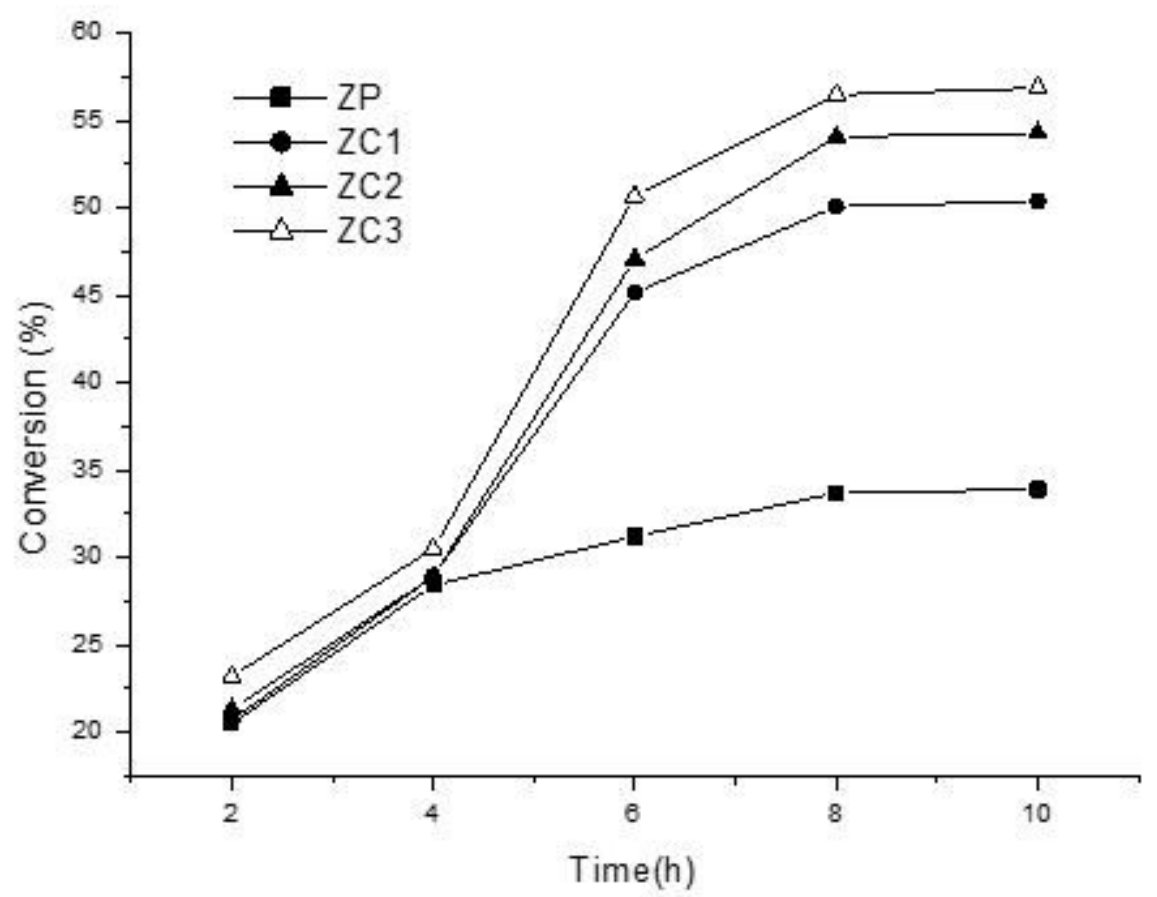

Figure 9

Comparison of conversions (\%) of esterification of benzyl alcohol with acetic acid over different catalysts at different time.

\section{Supplementary Files}

This is a list of supplementary files associated with this preprint. Click to download.

- relations.docx 